\title{
Association between per capita sugar consumption and diabetes prevalence mediated by the body mass index: results of a global mediation analysis
}

\author{
Alexander Lang ${ }^{1} \cdot$ Oliver Kuss $^{1,3} \cdot$ Tim Filla $^{2} \cdot$ Sabrina Schlesinger ${ }^{1,3}$ (D) \\ Received: 26 March 2020 / Accepted: 25 September 2020 / Published online: 9 October 2020 \\ (c) The Author(s) 2020
}

\begin{abstract}
Purpose The aim of this study was to examine the mediation of body mass index (BMI) on the association between per capita sugar consumption and diabetes prevalence using country-related data.

Research design and methods In this ecological study, based on 192 countries, data on per capita sugar consumption were obtained from the Food and Agriculture Organization of the United Nations (FAO), on BMI from the World Health Organization and on diabetes prevalence from the International Diabetes Federation. Data on demography and economic factors were obtained from the Central Intelligence Agency, the United Nations and the FAO. Multiple linear regression analysis was performed to investigate the association between per capita sugar consumption and diabetes prevalence, and mediation analysis to detect the mediated percentage of BMI on this association.

Results Each increase of $100 \mathrm{kcal} /$ day per capita sugar consumption was associated with a $1.62 \%$ higher diabetes prevalence [adjusted $\beta$-estimator $(95 \% \mathrm{CI}): 1.62(0.71,2.53)$ ]. Mediation analysis using BMI as the mediator demonstrated an adjusted direct association of 0.55 (95\% CI: - 0.22, 1.32) and an adjusted indirect association of 1.07 (95\% CI: 0.54, 1.68). Accordingly, the BMI explained 66\% (95\% CI: 34\%, 100\%) of the association between per capita sugar consumption on diabetes prevalence.

Conclusions These findings indicate that the association between dietary sugar intake and the occurrence of diabetes is mediated by BMI to a large proportion. However, it seems that other mechanisms may explain the association between sugar consumption and development of type 2 diabetes.
\end{abstract}

Keywords Diabetes $\cdot$ Ecological study $\cdot$ Mediation $\cdot$ Obesity $\cdot$ Sugar

Electronic supplementary material The online version of this article (https://doi.org/10.1007/s00394-020-02401-2) contains supplementary material, which is available to authorized users.

Sabrina Schlesinger

Sabrina.Schlesinger@ddz.de

1 Institute for Biometrics and Epidemiology, German Diabetes Center, Leibniz Institute for Diabetes Research at Heinrich Heine University Düsseldorf, Auf'm Hennekamp 65, 40225 Düsseldorf, Germany

2 Institute for Biometrics and Bioinformatics, University Hospital Düsseldorf, Research at Heinrich Heine University Düsseldorf, Moorenstraße 5, 40225 Düsseldorf, Germany

3 German Center for Diabetes Research (DZD e.V.), München-Neuherberg, Germany

\section{Introduction}

There is an ongoing debate whether dietary sugar intake has an impact on the development of type 2 diabetes (T2D). In the last decades, per capita sugar consumption increased, particularly in developing and emerging countries [1], due to demographic growth, rising income and increasing availability of sugar containing products [2]. On the contrary, per capita sugar consumption was stable or decreasing in developed countries [1,3]. Nevertheless, per capita sugar consumption still remains high in western civilizations [1,4]. Along with the high intake of dietary sugar, there has been a large increase in the incidence of T2D, which is a heterogeneous disease and caused by environmental as wells as genetic components. Several risk factors are known, including, e.g., age, overweight or obesity, or family history of diabetes 
$[5,6]$. During the last decades, lifestyle factors, including dietary behaviour have been recognised as important predictive factors for the development and progression of T2D [7]. For dietary factors, high certainty of evidence was observed for lower incidence of T2D for a healthy dietary pattern, including high intake of fibre from whole grain products and low intake of red meat and sugar sweetened beverages [8]. In this context, a high intake of dietary sugar may contribute to an overload of calorie intake and may lead to obesity [9], which is a causal risk factor for T2D [10]. Furthermore, direct pathophysiologic mechanisms due to glycaemic effects independent of overweight and obesity via, e.g., an increase of liver fat content or specific adipose tissues [11, 12], might explain the association between dietary sugar intake, particularly fructose and sugar sweetened beverages intake, and risk of T2D [13-16].

However, findings from observational studies on the relation between total dietary sugar intake and T2D incidence were inconsistent. While an increase of sugar sweetened beverage consumption was consistently associated with T2D [8, 17, 18], the evidence regarding the association between the intake of mono- and disaccharides regarding development of T2D is insufficient [8]. In a systematic review and meta-analysis, associations between total dietary sugar intake and T2D were summarized and higher intake of total sugar was inversely, but imprecisely estimated, associated with incidence of T2D [19]. There was heterogeneity between the studies, and risk estimates pointed to an inverse direction [20] or null associations [21-25], respectively. In addition, the meta-analysis summarized findings between fructose and sucrose intake and risk of T2D and reported inverse relationships [19], but again, the results of the single studies were heterogeneous and pointed to different directions. Moreover, some of the studies indicated that the body mass index (BMI) might bias this relationship [21, 24, 25]. Nevertheless, findings of observational studies need to be interpreted with caution, since dietary sugar intake is measured in general by self-reports of the participants, which is prone to bias, because participants, particularly overweight participants, tend to underreport their true intake of unhealthy food [26-28]. Findings from ecological studies, based on aggregated estimations of per capita sugar consumption showed a positive correlation with diabetes prevalence at country level [29-31]. However, in these studies, the impact of BMI on the association between dietary sugar intake and diabetes prevalence was not considered yet. Thus, we conducted a global ecological study to investigate the direct association between dietary sugar consumption and T2D and the indirect association mediated via the BMI using aggregated data from single countries.

\section{Methods}

\section{Study design}

This is a mediation analysis based on an ecological study design, including geographical group-level country data. The study is reported according to the Guidelines for Accurate and Transparent Health Estimates Reporting (GATHER) [32], and Strengthening the Reporting of Observational Studies in Epidemiology-Nutritional Epidemiology (STROBE-nut) [33]. Data from several official data-collection sources were obtained on: per capita sugar consumption (exposure), diabetes prevalence (outcome), and BMI (mediator). Since this is a mediation analyses, we considered the "causal pathways" between dietary sugar intake and obesity [9], and consequently, between obesity and incidence of T2D [10], and thus decided to assess our data in an a priori defined time-sequence of 5 year intervals. In addition, we selected available potential confounders a prior [34]: mean age [35], per capita gross domestic product (GDP) as a socioeconomic variable [36], per capita fat intake [8], total energy supply [37] and percentage of rural population [38]. All considered data were based on estimations. For sensitivity analysis data on prevalence of overweight $\left(\right.$ BMI $\geq 25 \mathrm{~kg} / \mathrm{m}^{2}-<30 \mathrm{~kg} / \mathrm{m}^{2}$ ) and obesity (BMI $\geq 30 \mathrm{~kg} /$ $\mathrm{m}^{2}$ ) were collected. All countries with available data on at least half of the considered variables were included in this study. Finally, for the present analysis data from 192 countries were selected (Supplement: Fig. 1).

\section{Data collection}

Data on per capita sugar consumption adjusted for exports and any kind of non-human consumption were obtained for the year 2007 from the Food and Agriculture Organization of the United Nations (FAO) that received the estimated data mainly from national statistical offices [39]. Per capita sugar consumption contains the food supply of raw centrifugal sugar of cane as well as beet, refined sugar, sugar confectionary and sugar flavoured products per person in kilocalories per day [39]. Mean BMI and the prevalence rates of overweight and obesity were collected for the year 2012 from the WHO [40]. Data on age-adjusted diabetes prevalence were obtained for the year 2017 from the International Diabetes Federation (IDF) which extracted the data from peer-reviewed articles, national health surveys and other official sources [41]. Matched to the acquisition of the exposure, data on all potential confounders were also obtained from 2007. Therefore, country-level per capita GDP was received from the statistics division of the United Nations (UN) [42]. Further, data on mean age were obtained from the Central Intelligence Agency (CIA) [43], and data on rural 
population, per capita fat intake and total energy supply per day were collected from the FAO [39, 44]. Energy supply is defined as the average per capita caloric availability, which means that this number does not necessarily indicate the real amount of calories that was actually consumed [39]. Countries were categorized as continents according to the classification of the UN [45]. For a sensitivity analysis, we collected the most recent data on per capita sugar consumption [39] and potential confounders (2013) [39, 42-44], BMI (2016) [40], and diabetes prevalence (2017) [41] from the same organizations.

\section{Statistical analysis}

Pearson's correlation coefficients were calculated to describe the correlations between per capita sugar consumption and diabetes prevalence, as well as between per capita sugar consumption and BMI, and between BMI and diabetes prevalence. Multiple linear regression analysis, adjusted for age, per capita GDP, per capita fat intake and total energy supply and rate of rural population, was accomplished to estimate the association between per capita sugar consumption and diabetes prevalence. We performed the mediation analysis by applying the method suggested by VanderWeele [46]. For this, the following criteria must be fulfilled: first, the exposure (per capita sugar consumption) has to be associated with the outcome (diabetes prevalence). Second, the exposure (per capita sugar consumption) has to be associated with the mediator (BMI), and third, the mediator (BMI) has to be associated with the outcome (diabetes prevalence). If the criteria are fulfilled, mediation analysis can be conducted to estimate the direct association of per capita sugar consumption [per $100 \mathrm{kcal} /$ day] on diabetes prevalence and the indirect association of this relation via the "causal pathway" of obesity (Fig. 1). If a total association between exposure and outcome exists, and the direct association is low, it can be interpreted that the association is mediated to

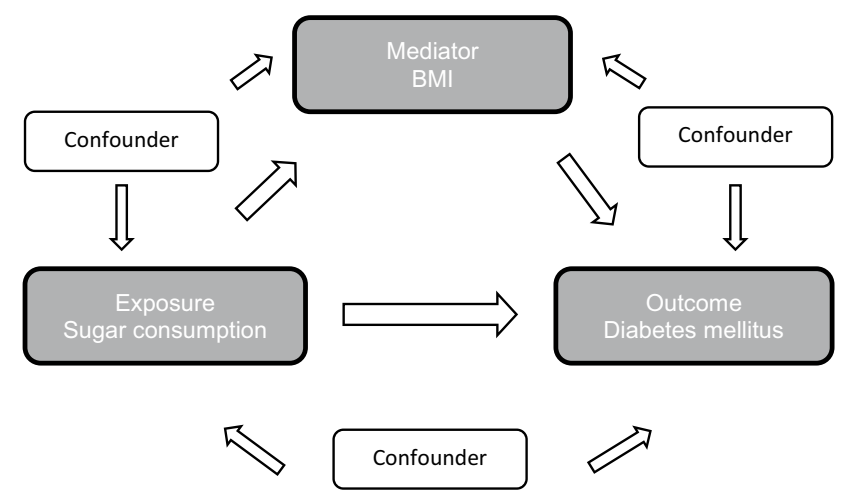

Fig. 1 Chart of the causal pathways regarding the association between sugar consumption and diabetes prevalence a large proportion by the mediator. In contrast, if the indirect association is low, it implicates that the potential mediator has little or no mediating impact on the association between exposure and outcome. Moreover, the mediated percentage can be calculated, which is defined as the quotient of the indirect association in relation to the total association, to estimate the percentage impact of BMI on the association between per capita sugar consumption and diabetes prevalence [46].

Standard multiple imputation methods were used to account for missing values, where for per capita sugar consumption $n=22$ were missing, for diabetes prevalence $n=4$, BMI $n=2$, age $n=1$, fat intake $n=24$, total energy $n=22$ and rural population $n=16$. All available variables were used for imputation and 1000 data sets were generated. The mediation model was calculated for each imputed data set, and we reported the median value from the 1000 model fits as the estimated parameter together with the $2.5 \%$ and $97.5 \%$ percentiles as the respective non-parametric $95 \%$ confidence interval (CI). If the 95\% CI does not include the null-value, the findings are estimated precisely and can be interpreted as "statistically significant". We chose this simultaneous application of multiple imputation and a non-parametric bootstrap procedure as there is still methodological debate on how confidence intervals for mediation parameters should be calculated. In addition, by combining the two approaches it is guaranteed that the complete statistical variability in the data is properly accounted for, yielding conservative confidence intervals that are rather too long than too short. Statistical analyses were performed in R 3.6.1 and SAS, Version 9.4 by the MI and the CAUSALMED procedure.

\section{Results}

After performing multiple imputation, data on 192 countries were assessed for analyses. The characteristics for the included countries are shown in Supplement: Tables 1-7 allocated by regions defined by the UN [47]. Mean (SD) per capita sugar consumption was $191 \pm 122 \mathrm{kcal} / \mathrm{d}$. Highest per capita sugar consumption was seen in Central America $(428 \pm 55 \mathrm{kcal} / \mathrm{d})$, Oceania $(407 \pm 86 \mathrm{kcal} / \mathrm{d})$ and Eastern Europe $(386 \pm 80 \mathrm{kcal} / \mathrm{d})$. Mean diabetes prevalence was $8.5 \pm 2.8 \%$, whereas highest diabetes prevalence was observed in Northern Africa (12.8 $\pm 5.7 \%)$, Central America $(12.6 \pm 2.0 \%)$ and Western Asia $(11.0 \pm 4.0 \%)$. Global mean BMI was $24.0 \pm 2.3 \mathrm{~kg} / \mathrm{m}^{2}$, with the highest mean BMI in Northern America $\left(28.4 \pm 1.0 \mathrm{~kg} / \mathrm{m}^{2}\right)$, Central America $\left(27.4 \pm 0.6 \mathrm{~kg} / \mathrm{m}^{2}\right)$ and Western Asia $\left(27.3 \pm 1.5 \mathrm{~kg} / \mathrm{m}^{2}\right)$.

Findings showed a positive correlation between per capita sugar consumption and diabetes prevalence (Pearson: $r=0.37$ (95\% CI: 0.24, 0.49), $p<0.01$ ). After stratification by region, this positive trend was observed for Asia $(r=0.56$ 
(95\% CI: 0.17, 0.80), $p=0.01)$ and Africa $(r=0.42$ (95\% CI: $-0.03,0.73), p=0.06)$, but not for Oceania $(r=-0.34(95 \%$ CI: $-0.97,0.86), p=0.67)$ and Europe $(r=-0.26(95 \%$ CI: $-0.64,0.23), p=0.30)$ (Supplement: Table 10). Similar findings between per capita sugar consumption and diabetes prevalence were observed after stratification by income classification, showing positive correlations for lower middle and upper middle income countries, and null associations for low and high income countries regarding the association between per capita sugar consumption and diabetes prevalence (Supplement: Table 11).

There was also positive correlations between per capita sugar consumption and mean BMI ( $r=0.67$ (95\% CI: 0.58, $0.75), p<0.01)$ and mean BMI and diabetes prevalence $(r=0.58$ (95\% CI: 0.46, 0.68), $p<0.01$ ), respectively (Supplement: Figs. 1 and 2). Correlation coefficients between exposure or outcome with potential confounding variables were positive for mean age, per capita GDP, per capita fat intake and total energy or inverse correlations for rural population (Supplement: Table 12).
Results of univariate linear regression models indicated a positive association of per capita sugar consumption with diabetes prevalence $(\beta(95 \% \mathrm{CI}): 1.42(0.72,2.13), p<0.01)$ and BMI ( $\beta$ (95\% CI): $1.18(0.91,1.45), p<0.01)$ (Supplement: Fig. 2), respectively. BMI was positively associated with diabetes prevalence $(\beta$ (95\% CI): $1.16(0.74,1.51)$, $p<0.01$ ) (Supplement: Fig. 3). Adjustment for BMI weakened the association between per capita sugar consumption and diabetes prevalence $(\beta$ (95\% CI): $0.12(-0.83,1.07)$, $p=0.81$ ), indicating that BMI is a mediator. In the multiple linear regression model adjusted for age, per capita GDP, per capita fat intake, total energy and rural population, each increase of per capita sugar consumption per $100 \mathrm{kcal} /$ day was associated with $1.62 \%$ higher diabetes prevalence $(\beta$ (95\% CI): $1.62(0.71,2.53), p<0.01)$ (Fig. 2). The findings of our mediation analysis showed an adjusted direct association of 0.55 (95\% CI: $-0.22,1.32)$ and an adjusted indirect association of 1.07 (95\% CI: 0.54, 1.68) regarding the relation between per capita sugar consumption and diabetes prevalence. According to this, the mediated percentage

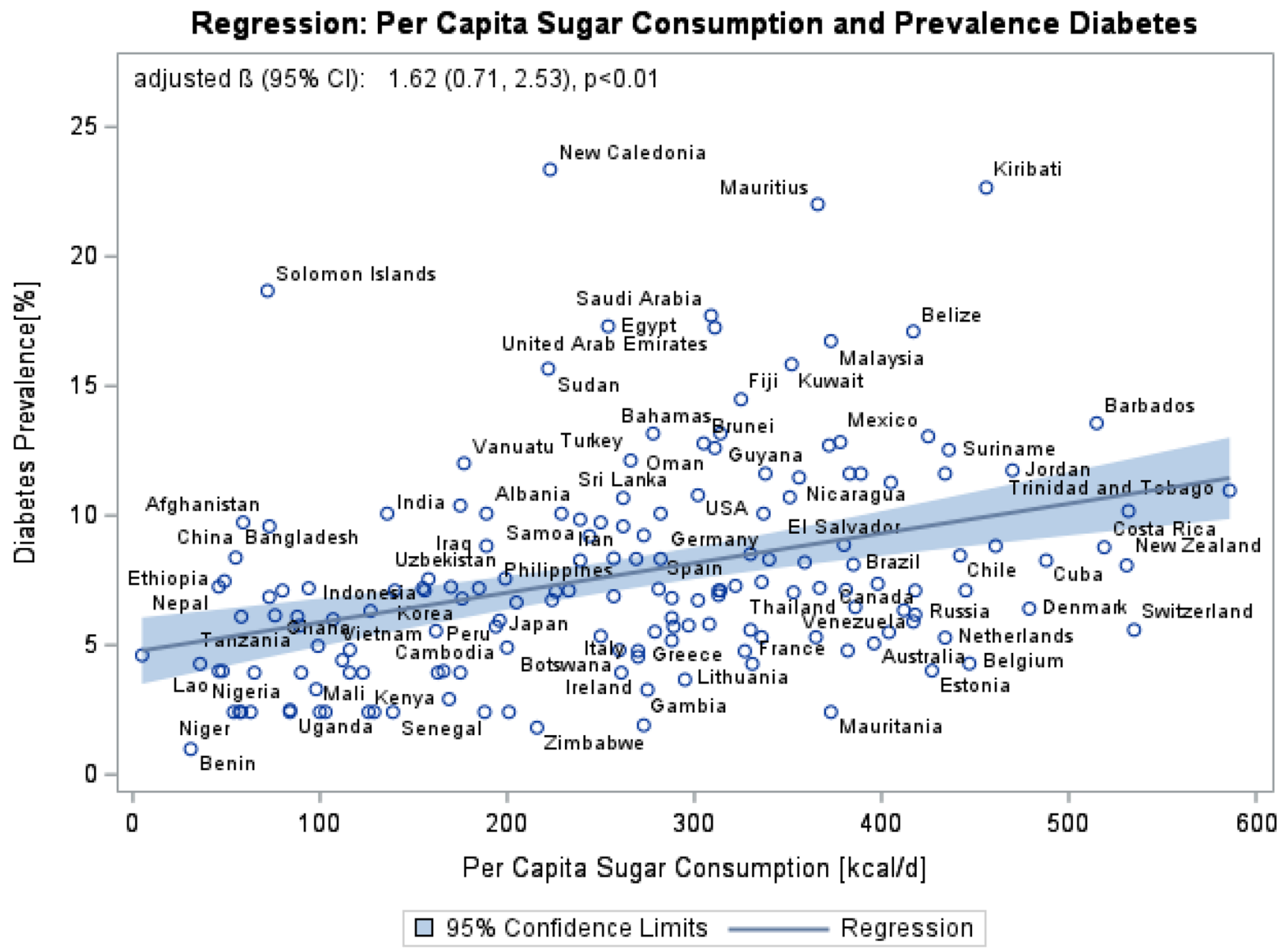

Fig. 2 Linear regression of per capita sugar consumption (2007-FAO) and diabetes prevalence (2017—IDF)—including 192 countries 
Table 1 Mediation analysis for BMI on the association between per capita sugar consumption per $100 \mathrm{kcal} /$ day and diabetes prevalence

\begin{tabular}{lll}
\hline & $\begin{array}{l}\text { Model 1 (crude) } \\
\beta[95 \% \mathrm{CI}]\end{array}$ & $\begin{array}{l}\text { Model 2 (adjusted)* } \\
\beta[95 \% \mathrm{CI}]\end{array}$ \\
\hline$\beta_{\text {total }}$ & $1.42[0.72,2.13]$ & $1.62[0.71,2.53]$ \\
$\beta_{\text {direct }}$ & $0.13[-0.67,0.87]$ & $0.55[-0.22,1.32]$ \\
$\beta_{\text {indirect }}$ & $1.28[0.71,2.00]$ & $1.07[0.54,1.68]$ \\
$\%$ mediated & $90.7 \%[48.6 \%, 100.0 \% * *]$ & $66.1 \%[34.4 \%, 100.0 \% * *]$ \\
\hline
\end{tabular}

*Adjusted for age [years] (2007-CIA), per capita gross domestic product [US\$] (2007-UN), total energy [kcal/day] (2007-FAO), per capita fat intake [g/d] (2007-FAO) and rural population [\%] (2007FAO)

**Bootstrap $95 \%$ CI cut off by $100 \%$

of BMI on this association was $66 \%$ (95\% CI: $34 \%, 100 \%)$ after adjusting for covariates (Table 1). In reverse, about one third of the total association between sugar consumption and prevalence of diabetes could be explained by other mechanisms.

Sensitivity analysis showed similar results when using the most recent data that were available (Supplement: Fig. 4 and Table 8). Performing mediation analysis using the prevalence of overweight or obesity as mediator, the adjusted mediated percentage was $40 \%$ (95\% CI: $15 \%, 78 \%$ ) for overweight, and 51\% (95\% CI: 23\%, 87\%) for obesity, respectively (Supplement Table 9).

\section{Discussion}

The findings of our ecological study showed an association between dietary sugar intake and prevalence of diabetes and suggested that the total association can be explained by about two thirds via BMI. In consequence, there might be other mechanisms that explain the association between dietary sugar intake and diabetes.

Regarding the impact of dietary sugar intake on the development of T2D, the evidence is inconclusive and findings are controversial $[8,19]$. Compared to other ecological analyses that have examined the association between per capita sugar consumption and diabetes prevalence, we received similar results regarding the relationship between dietary sugar intake and diabetes prevalence [29-31]. Moreover, several studies indicated that consumption of sugar sweetened beverages was associated with weight gain and increased T2D risk $[8,17,18]$. However, findings of observational studies reported an inverse relation [20] or no associations [21-25] concerning the association between total dietary sugar intake and risk of T2D. Nevertheless, some of these studies suggested an inverse association which disappeared after adjusting for BMI [21, 24, 25].

These observations indicate that reporting bias dependent on BMI status cannot be ruled out. Since nutrition data is mainly based on self-reports of participants, it is likely that intake of unhealthy food, including sugar containing products, can be biased due to measurement errors, because especially, overweight participants tend to underreport their true intake [26-28]. As a result of this, other reliable methods to assess dietary sugar intake, like measuring a sucrose biomarker, e.g., in urine samples, should be used in the future to eliminate recall bias [48, 49]. Some studies already investigated objective sucrose biomarker and found deviations in comparison to dietary sugar intake assessed with Food Frequency Questionnaires (FFQ) or 24-h dietary recalls (24HRs) [49, 50]. In addition, various cross-sectional studies investigated stable isotope ratios of carbon $\left(\delta^{13} \mathrm{C}\right)$ and nitrogen $\left(\delta^{15} \mathrm{~N}\right)$ as potential sugar biomarker in adults measured in hair, capillary finger stick blood and blood serum [51-54]. Findings of these studies indicated that $\delta^{13} \mathrm{C}$ might potentially be an objective biomarker to assess dietary sugar intake, since $\delta 13 \mathrm{C}$ values were predictive for the intake of added sugar [52-54], sugar sweetened beverages [51-53], as well as total sugar intake [54]. However, findings concerning $\delta^{15} \mathrm{~N}$ biomarker were inconclusive predicting sugar intake. While results in an Alaska native study population showed a strong association between $\delta^{15} \mathrm{~N}$ and dietary sugar intake [54], findings of another population did not show any association [53].

The present body of research implies that an increased body weight might be the major explanation for the observed association between dietary sugar intake and diabetes prevalence. A high dietary sugar intake may lead to overweight and obesity which is associated with increased risk of T2D. Since the amount of adipose tissue is enlarged, overweight and obesity increase the secretion of nonesterified fatty acids and different hormones and cytokines, such as leptin, adiponectin and pro-inflammatory cytokines, which are associated with insulin resistance $[55,56]$. In addition, obesity can cause a decrease in $\beta$-cell function [55], which leads to the development of T2D over time [57]. Moreover, as our results indicated, other possible pathophysiologic mechanisms, independent of the influence of overweight and obesity, might explain the association between dietary sugar intake and the development of diabetes. For example, intake of large amounts of added sugars can contribute to a diet with high glycaemic load which can induce higher glycaemic and insulinemic response [15]. Findings from observational studies have shown that diets with high glycaemic loads were associated with increased risk of T2D $[58,59]$. A possible explanation for this observation could be a decrease in insulin sensitivity $[60,61]$, which can progress to T2D [59, 62]. In addition, different types of sugars might have different effects on insulin resistance and blood glucose control. Recently, a systematic review and network meta-analysis showed that the dietary isocaloric exchange 
of fructose with glucose had a beneficial effect on insulin resistance [63]. A further explanation for an association between sugar intake and T2D could be the development of non-alcoholic fatty liver disease (NAFLD), which has shown a bidirectional association with T2D [64, 65]. Dietary sugar intake, especially fructose intake, has been linked to an increase in liver fat content and NAFLD [11, 12], which is strongly associated with insulin resistance [66].

Our study had several strengths. This was the first study performing a causal mediation analysis that investigated the impact of BMI as mediator for the association between per capita sugar consumption and diabetes prevalence. Besides this, the used data, including potential economic and healthrelated confounders, were current and obtained from reliable global organisations. Furthermore, we considered lead time intervals between exposure, mediator and outcome to simulate a prospective sequence between these factors. However, our study had some limitations as well. First, conclusions about causality are hampered due to the ecological study design. Future prospective studies are needed to ascertain more reliable findings regarding the direct association between dietary sugar intake and incidence of T2D based on individual data while using objective biomarkers to assess the true dietary sugar intake. Second, data regarding diabetes prevalence obtained from the IDF also contained individuals with type 1 diabetes or other types of diabetes, which might be approximately around $7-12 \%$ and $1-3 \%$ in high income countries, respectively [41]. This may affect the results due to, e.g., different body composition compared to individuals with T2D. Overall, the collected population-related data are mainly not based on individual assessments, but on estimations and projections, especially for developing countries due to insufficient opportunity of central data collection. Accordingly, data quality might differ due to differences in surveillance infrastructure between countries. Moreover, supply data as it was used for per capita sugar consumption, fat and total energy intake might not reflect the actual intake of an individual, but only the amount reaching the consumer [39]. Hence, obtained data may differ from the true values $[39,41]$. Beyond that, confounding cannot be ruled out, because relevant data, e.g., further dietary factors, physical activity, or smoking, were not available and thus, could not be considered in this analysis. Consequently, additional potential confounders should be considered in future research.

\section{Conclusions}

In this ecological study, per capita sugar consumption was positively associated with diabetes prevalence at a global level. This association was mediated by $66 \%$ by BMI, indicating, that a large amount of this association can be explained by BMI, but that also other mechanisms exist that could explain the association between dietary sugar intake and the development of T2D. Causality cannot be proved with an ecological study design, and thus further well-conducted studies are recommended that use individual participant data and valid measurements for their sugar consumption.

Author contributions SS and OK designed the research. AL extracted the data and performed the analyses with support of TF and OK. AL and SS interpreted the data and wrote the first draft of the paper. All authors read the manuscript and approved the final version. AL and SS are guarantors. The corresponding author attests that all listed authors meet authorship criteria and that no others meeting the criteria were omitted.

Funding Open Access funding enabled and organized by Projekt DEAL. The German Diabetes Centre is funded by the German Federal Ministry of Health and the Ministry of Innovation, Science, Research and Technology of the State North Rhine-Westphalia. The funding source has no role in the decisions about the data collection, analysis, interpretation of the data, preparation, review or approval of the manuscript.

Data availability Data were extracted from several official data-collection sources, all of which are publicly available and accessible.

Code availability Will be provided if requested.

\section{Compliance with ethical standards}

Conflict of interest All authors have completed the ICMJE uniform disclosure form at www.icmje.org/coi_disclosure.pdf and declare: support from the German Federal Ministry of Health, the Ministry of Innovation, Science, Research and Technology of the State North Rhine-Westphalia; no financial relationships with any organisations that might have an interest in the submitted work in the previous 3 years; no other relationships or activities that could appear to have influenced the submitted work.

Ethical approval No ethical approval is required due to study design.

Consent to participate Not applicable due to study design.

Consent of publication Not applicable due to study design.

Open Access This article is licensed under a Creative Commons Attribution 4.0 International License, which permits use, sharing, adaptation, distribution and reproduction in any medium or format, as long as you give appropriate credit to the original author(s) and the source, provide a link to the Creative Commons licence, and indicate if changes were made. The images or other third party material in this article are included in the article's Creative Commons licence, unless indicated otherwise in a credit line to the material. If material is not included in the article's Creative Commons licence and your intended use is not permitted by statutory regulation or exceeds the permitted use, you will need to obtain permission directly from the copyright holder. To view a copy of this licence, visit http://creativecommons.org/licenses/by/4.0/. 


\section{References}

1. Organisation for Economic Co-operation and Development Food Agriculture Organization. Agriculture Outlook 2019-2028. Retrieved from https://www.fao.org/3/CA4076EN/CA4076EN_ Chapter5_Sugar.pdf. Accessed July 15

2. Schmidhuber J, Shetty P (2005) The nutrition transition to 2030. Why developing countries are likely to bear the major burden. Food Econ Acta Agricu Scand Section C 2(3-4):150-166. https ://doi.org/10.1080/16507540500534812

3. Wittekind A, Walton J (2014) Worldwide trends in dietary sugars intake. Nutr Res Rev 27(2):330-345. https://doi.org/10.1017/ S0954422414000237

4. Johnson RK, Appel LJ, Brands M, Howard BV, Lefevre M, Lustig RH, Sacks F, Steffen LM, Wylie-Rosett J, American Heart Association Nutrition Committee of the Council on Nutrition PA, Metabolism, the Council on E, Prevention (2009) Dietary sugars intake and cardiovascular health: a scientific statement from the American Heart Association. Circulation 120(11):1011-1020. https://doi.org/10.1161/CIRCULATIONAHA.109.192627

5. Cuschieri S (2019) The genetic side of type 2 diabetes - a review. Diabetes Metab Syndr 13(4):2503-2506. https://doi.org/10.1016/j. dsx.2019.07.012

6. Fletcher B, Gulanick M, Lamendola C (2002) Risk factors for type 2 diabetes mellitus. J Cardiovasc Nurs 16(2):17-23. https ://doi.org/10.1097/00005082-200201000-00003

7. Schlesinger S, Neuenschwander M, Ballon A, Nothlings U, Barbaresko J (2020) Adherence to healthy lifestyles and incidence of diabetes and mortality among individuals with diabetes: a systematic review and meta-analysis of prospective studies. J Epidemiol Community Health 74(5):481-487. https://doi. org/10.1136/jech-2019-213415

8. Neuenschwander M, Ballon A, Weber KS, Norat T, Aune D, Schwingshackl L, Schlesinger S (2019) Role of diet in type 2 diabetes incidence: umbrella review of meta-analyses of prospective observational studies. BMJ 366:12368. https://doi. org/10.1136/bmj.12368

9. Te Morenga L, Mallard S, Mann J (2012) Dietary sugars and body weight: systematic review and meta-analyses of randomised controlled trials and cohort studies. BMJ 346:e7492. https://doi.org/10.1136/bmj.e7492

10. Abdullah A, Peeters A, de Courten M, Stoelwinder J (2010) The magnitude of association between overweight and obesity and the risk of diabetes: a meta-analysis of prospective cohort studies. Diabetes Res Clin Pract 89(3):309-319. https://doi. org/10.1016/j.diabres.2010.04.012

11. Ouyang X, Cirillo P, Sautin Y, McCall S, Bruchette JL, Diehl AM, Johnson RJ, Abdelmalek MF (2008) Fructose consumption as a risk factor for non-alcoholic fatty liver disease. J Hepatol 48(6):993-999. https://doi.org/10.1016/j.jhep.2008.02.011

12. Assy N, Nasser G, Kamayse I, Nseir W, Beniashvili Z, Djibre A, Grosovski M (2008) Soft drink consumption linked with fatty liver in the absence of traditional risk factors. Can J Gastroenterol 22(10):811-816. https://doi.org/10.1155/2008/810961

13. Choo VL, Viguiliouk E, Blanco Mejia S, Cozma AI, Khan TA, Ha V, Wolever TMS, Leiter LA, Vuksan V, Kendall CWC, de Souza RJ, Jenkins DJA, Sievenpiper JL (2018) Food sources of fructose-containing sugars and glycaemic control: systematic review and meta-analysis of controlled intervention studies. BMJ 363:k4644. https://doi.org/10.1136/bmj.k4644

14. Evans RA, Frese M, Romero J, Cunningham JH, Mills KE (2017) Chronic fructose substitution for glucose or sucrose in food or beverages has little effect on fasting blood glucose, insulin, or triglycerides: a systematic review and meta-analysis.
Am J Clin Nutr 106(2):519-529. https://doi.org/10.3945/ ajen.116.145169

15. Malik VS, Hu FB (2012) Sweeteners and risk of obesity and type 2 diabetes: the role of sugar-sweetened beverages. Curr Diab Rep. https://doi.org/10.1007/s11892-012-0259-6

16. Raben A, Moller BK, Flint A, Vasilaris TH, Christina Moller A, Juul Holst J, Astrup A (2011) Increased postprandial glycaemia, insulinemia, and lipidemia after 10 weeks' sucrose-rich diet compared to an artificially sweetened diet: a randomised controlled trial. Food Nutr Res. https://doi.org/10.3402/fnr.v55i0.5961

17. Imamura F, O'Connor L, Ye Z, Mursu J, Hayashino Y, Bhupathiraju SN, Forouhi NG (2015) Consumption of sugar sweetened beverages, artificially sweetened beverages, and fruit juice and incidence of type 2 diabetes: systematic review, meta-analysis, and estimation of population attributable fraction. BMJ 351:h3576. https://doi.org/10.1136/bmj.h3576

18. Malik VS, Popkin BM, Bray GA, Despres JP, Willett WC, Hu FB (2010) Sugar-sweetened beverages and risk of metabolic syndrome and type 2 diabetes: a meta-analysis. Diabetes Care 33(11):2477-2483. https://doi.org/10.2337/dc10-1079

19. Tsilas CS, de Souza RJ, Mejia SB, Mirrahimi A, Cozma AI, Jayalath VH, Ha V, Tawfik R, Di Buono M, Jenkins AL, Leiter LA, Wolever TMS, Beyene J, Khan T, Kendall CWC, Jenkins DJA, Sievenpiper JL (2017) Relation of total sugars, fructose and sucrose with incident type 2 diabetes: a systematic review and meta-analysis of prospective cohort studies. CMAJ 189(20):E711E720. https://doi.org/10.1503/cmaj.160706

20. Hodge AM, English DR, O’Dea K, Giles GG (2004) Glycemic index and dietary fiber and the risk of type 2 diabetes. Diabetes Care 27(11):2701-2706. https://doi.org/10.2337/diaca re.27.11.2701

21. Janket SJ, Manson JE, Sesso H, Buring JE, Liu S (2003) A prospective study of sugar intake and risk of type 2 diabetes in women. Diabetes Care 26(4):1008-1015. https://doi.org/10.2337/ diacare.26.4.1008

22. Barclay AW, Flood VM, Rochtchina E, Mitchell P, Brand-Miller JC (2007) Glycemic index, dietary fiber, and risk of type 2 diabetes in a cohort of older Australians. Diabetes Care 30(11):28112813. https://doi.org/10.2337/dc07-0784

23. Montonen J, Jarvinen R, Knekt P, Heliovaara M, Reunanen A (2007) Consumption of sweetened beverages and intakes of fructose and glucose predict type 2 diabetes occurrence. J Nutr 137(6):1447-1454. https://doi.org/10.1093/jn/137.6.1447

24. Sluijs I, Beulens JW, van der Schouw YT, Buckland G, Kuijsten A, Schulze MB, Amiano P, Ardanaz E, Balkau B, Boeing H, Gavrila D, Grote VA, Key TJ, Li K, Nilsson P, Overvad K, Palli D, Panico S, Quiros JR, Rolandsson O, Roswall N, Sacerdote C, Sanchez MJ, Sieri S, Slimani N, Spijkerman AM, Tjonneland A, Tumino R, Sharp SJ, Langenberg C, Feskens EJ, Forouhi NG, Riboli E, Wareham NJ, InterAct c (2013) Dietary glycemic index, glycemic load, and digestible carbohydrate intake are not associated with risk of type 2 diabetes in eight European countries. J Nutr 143(1):93-99. https://doi.org/10.3945/jn.112.165605

25. Ahmadi-Abhari S, Luben RN, Powell N, Bhaniani A, Chowdhury R, Wareham NJ, Forouhi NG, Khaw KT (2014) Dietary intake of carbohydrates and risk of type 2 diabetes: the European prospective investigation into cancer-Norfolk study. Br J Nutr 111(2):342352. https://doi.org/10.1017/S0007114513002298

26. Lutomski JE, van den Broeck J, Harrington J, Shiely F, Perry IJ (2011) Sociodemographic, lifestyle, mental health and dietary factors associated with direction of misreporting of energy intake. Public Health Nutr 14(3):532-541. https://doi.org/10.1017/S1368 980010001801

27. Gottschald M, Knuppel S, Boeing H, Buijsse B (2016) The influence of adjustment for energy misreporting on relations of cake and cookie intake with cardiometabolic disease risk factors. 
Eur J Clin Nutr 70(11):1318-1324. https://doi.org/10.1038/ ejcn.2016.131

28. Bedard D, Shatenstein B, Nadon S (2004) Underreporting of energy intake from a self-administered food-frequency questionnaire completed by adults in Montreal. Public Health Nutr 7(5):675-681. https://doi.org/10.1079/PHN2003578

29. Basu S, Yoffe P, Hills N, Lustig RH (2013) The relationship of sugar to population-level diabetes prevalence: an econometric analysis of repeated cross-sectional data. PLoS ONE 8(2):e57873. https://doi.org/10.1371/journal.pone.0057873

30. Weeratunga P, Jayasinghe S, Perera Y, Jayasena G, Jayasinghe S (2014) Per capita sugar consumption and prevalence of diabetes mellitus-global and regional associations. BMC Public Health 14:186. https://doi.org/10.1186/1471-2458-14-186

31. Siervo M, Montagnese C, Mathers JC, Soroka KR, Stephan BC, Wells JC (2014) Sugar consumption and global prevalence of obesity and hypertension: an ecological analysis. Public Health Nutr 17(3):587-596. https://doi.org/10.1017/S1368980013000141

32. Stevens GA, Alkema L, Black RE, Boerma JT, Collins GS, Ezzati M, Grove JT, Hogan DR, Hogan MC, Horton R, Lawn JE, Marušić A, Mathers CD, Murray CJL, Rudan I, Salomon JA, Simpson PJ, Vos T, Welch V (2016) Guidelines for accurate and transparent health estimates reporting: the GATHER statement. The Lancet 388(10062):e19-e23. https://doi.org/10.1016/s0140 $-6736(16) 30388-9$

33. Lachat C, Hawwash D, Ocke MC, Berg C, Forsum E, Hornell A, Larsson C, Sonestedt E, Wirfalt E, Akesson A, Kolsteren P, Byrnes G, De Keyzer W, Van Camp J, Cade JE, Slimani N, Cevallos M, Egger M, Huybrechts I (2016) Strengthening the reporting of observational studies in epidemiology-nutritional epidemiology (STROBE-nut): an extension of the STROBE statement. PLoS Med 13(6):e1002036. https://doi.org/10.1371/ journal.pmed.1002036

34. VanderWeele TJ (2019) Principles of confounder selection. Eur J Epidemiol 34(3):211-219. https://doi.org/10.1007/s1065 4-019-00494-6

35. Cho NH, Shaw JE, Karuranga S, Huang Y, da Rocha Fernandes JD, Ohlrogge AW, Malanda B (2018) IDF Diabetes Atlas: global estimates of diabetes prevalence for 2017 and projections for 2045. Diabetes Res Clin Pract 138:271-281. https:// doi.org/10.1016/j.diabres.2018.02.023

36. Kivimäki M, Virtanen M, Kawachi I, Nyberg ST, Alfredsson L, Batty GD, Bjorner JB, Borritz M, Brunner EJ, Burr H, Dragano N, Ferrie JE, Fransson EI, Hamer M, Heikkilä K, Knutsson A, Koskenvuo M, Madsen IEH, Nielsen ML, Nordin M, Oksanen T, Pejtersen JH, Pentti J, Rugulies R, Salo P, Siegrist J, Steptoe A, Suominen S, Theorell T, Vahtera J, Westerholm PJM, Westerlund H, Singh-Manoux A, Jokela M (2015) Long working hours, socioeconomic status, and the risk of incident type 2 diabetes: a meta-analysis of published and unpublished data from 222120 individuals. Lancet Diabetes Endocrinol 3(1):27-34. https://doi.org/10.1016/s2213-8587(14)70178-0

37. Tinker LF, Sarto GE, Howard BV, Huang Y, Neuhouser ML, Mossavar-Rahmani Y, Beasley JM, Margolis KL, Eaton CB, Phillips LS, Prentice RL (2011) Biomarker-calibrated dietary energy and protein intake associations with diabetes risk among postmenopausal women from the Women's Health Initiative. Am J Clin Nutr 94(6):1600-1606. https://doi.org/10.3945/ ajen.111.018648

38. O'Connor A, Wellenius G (2012) Rural-urban disparities in the prevalence of diabetes and coronary heart disease. Public Health 126(10):813-820. https://doi.org/10.1016/j.puhe.2012.05.029

39. Food Agriculture Organization. FAOSTAT, Data Archives, Food Balance Sheets. 2013. Retrieved from: https://www.fao.org/faost at/en/\#data. Accessed 16 Jan 2020
40. World Health Organisation. Global Health Observatory data. Overweight and obesity. 2016. Retrieved from https://www.who. int/gho/ncd/risk_factors/overweight/en/. Accessed 16 Jan 2020

41. International Diabetes Federation. IDF Diabetes Atlas. 2017. Retrieved from: https://www.diabetesatlas.org/en/resources/. Accessed 16 Jan 2020

42. United Nations. Statistics Devision. National Accounts. 2016. Retrieved from: https://unstats.un.org/unsd/snaama/downloads. Accessed 16 Jan 2020

43. Central Intelligence Agency.The World Factbook. Median Age. 2017. Retrieved from: https://www.cia.gov/library/publications/ the-world-factbook/rankorder/2177rank.html\#qa. Accessed 16 Jan 2020

44. Food Agriculture Organization. FAOSTAT. Selected Indicators. FAO Statistical Yearbook. 2016. Retrieved from: https://www.fao. org/faostat/en/\#country. Accessed 16 Jan 2020

45. United Nations. Population division. Classification of countries by region, income group and subregion of the world. 2017. Retrieved from: https://population.un.org/wpp/General/Files/Definition_of_ Regions.pdf. Accessed 16 Jan 2020

46. VanderWeele TJ (2016) Mediation analysis: a practitioner's guide. Annu Rev Public Health 37:17-32. https://doi.org/10.1146/annur ev-publhealth-032315-021402

47. Glezer MG, Vygodin VA (2019) Evaluation of the antianginal effectiveness of trimetazidine in a new dosage form for a single dose, depending on the region of the Russian Federation. ODA trial results. Kardiologiia 59(10s):52-63. https://doi.org/10.18087 /cardio.n541

48. Tasevska N (2015) Urinary sugars-a biomarker of total sugars intake. Nutrients 7(7):5816-5833. https://doi.org/10.3390/nu707 5255

49. Kuhnle GG, Tasevska N, Lentjes MA, Griffin JL, Sims MA, Richardson L, Aspinall SM, Mulligan AA, Luben RN, Khaw KT (2015) Association between sucrose intake and risk of overweight and obesity in a prospective sub-cohort of the European prospective investigation into cancer in Norfolk (EPIC-Norfolk). Public Health Nutr 18(15):2815-2824. https://doi.org/10.1017/S1368 980015000300

50. Tasevska N, Midthune D, Tinker LF, Potischman N, Lampe JW, Neuhouser ML, Beasley JM, Van Horn L, Prentice RL, Kipnis V (2014) Use of a urinary sugars biomarker to assess measurement error in self-reported sugars intake in the nutrition and physical activity assessment study (NPAAS). Cancer Epidemiol Biomarkers Prev 23(12):2874-2883. https://doi.org/10.1158/1055-9965. Epi-14-0594

51. Fakhouri TH, Jahren AH, Appel LJ, Chen L, Alavi R, Anderson CA (2014) Serum carbon isotope values change in adults in response to changes in sugar-sweetened beverage intake. J Nutr 144(6):902-905. https://doi.org/10.3945/jn.113.186213

52. Hedrick VE, Davy BM, Wilburn GA, Jahren AH, Zoellner JM (2016) Evaluation of a novel biomarker of added sugar intake (delta 13C) compared with self-reported added sugar intake and the Healthy Eating Index-2010 in a community-based, rural US sample. Public Health Nutr 19(3):429-436. https://doi. org/10.1017/S136898001500107X

53. Hedrick VE, Zoellner JM, Jahren AH, Woodford NA, Bostic JN, Davy BM (2015) A dual-carbon-and-nitrogen stable isotope ratio model is not superior to a single-carbon stable isotope ratio model for predicting added sugar intake in southwest virginian adults. J Nutr 145(6):1362-1369. https://doi.org/10.3945/jn.115.211011

54. Nash SH, Kristal AR, Hopkins SE, Boyer BB, O’Brien DM (2014) Stable isotope models of sugar intake using hair, red blood cells, and plasma, but not fasting plasma glucose, predict sugar intake in a Yup'ik study population. J Nutr 144(1):75-80. https://doi. org/10.3945/jn.113.182113 
55. Al-Goblan AS, Al-Alfi MA, Khan MZ (2014) Mechanism linking diabetes mellitus and obesity. Diabetes Metab Syndr Obes 7:587-591. https://doi.org/10.2147/DMSO.S67400

56. Kahn S, Hull R, Utzschneider K (2006) Mechanisms linking obesity to insulin resistance and type 2 diabetes. Nature 444:840-846. https://doi.org/10.1038/nature05482

57. Halban PA, Polonsky KS, Bowden DW, Hawkins MA, Ling C, Mather KJ, Powers AC, Rhodes CJ, Sussel L, Weir GC (2014) beta-cell failure in type 2 diabetes: postulated mechanisms and prospects for prevention and treatment. Diabetes Care 37(6):17511758. https://doi.org/10.2337/dc14-0396

58. Greenwood DC, Threapleton DE, Evans CE, Cleghorn CL, Nykjaer C, Woodhead C, Burley VJ (2013) Glycemic index, glycemic load, carbohydrates, and type 2 diabetes: systematic review and dose-response meta-analysis of prospective studies. Diabetes Care 36(12):4166-4171. https://doi.org/10.2337/dc13-0325

59. Buyken AE, Mitchell P, Ceriello A, Brand-Miller J (2010) Optimal dietary approaches for prevention of type 2 diabetes: a lifecourse perspective. Diabetologia 53(3):406-418. https://doi. org/10.1007/s00125-009-1629-8

60. Kahlhofer J, Karschin J, Silberhorn-Buhler H, Breusing N, BosyWestphal A (2016) Effect of low-glycemic-sugar-sweetened beverages on glucose metabolism and macronutrient oxidation in healthy men. Int J Obes (Lond) 40(6):990-997. https://doi. org/10.1038/ijo.2016.25
61. Yoshida M, McKeown NM, Rogers G, Meigs JB, Saltzman E, D'Agostino R, Jacques PF (2007) Surrogate markers of insulin resistance are associated with consumption of sugar-sweetened drinks and fruit juice in middle and older-aged adults. J Nutr 137(9):2121-2127. https://doi.org/10.1093/jn/137.9.2121

62. Ludwig DS (2002) The glycemic index: physiological mechanisms relating to obesity, diabetes, and cardiovascular disease. JAMA 287(18):2414-2423. https://doi.org/10.1001/jama.287.18.2414

63. Schwingshackl L, Neuenschwander M, Hoffmann G, Buyken AE, Schlesinger S (2020) Dietary sugars and cardiometabolic risk factors: a network meta-analysis on isocaloric substitution interventions. Am J Clin Nutr 111(1):187-196. https://doi.org/10.1093/ ajcn/nqz273

64. Tilg H, Moschen AR, Roden M (2017) NAFLD and diabetes mellitus. Nat Rev Gastroenterol Hepatol 14(1):32-42. https://doi. org/10.1038/nrgastro.2016.147

65. Xia MF, Bian H, Gao X (2019) NAFLD and diabetes: two sides of the same coin? rationale for gene-based personalized NAFLD treatment. Front Pharmacol 10:877. https://doi.org/10.3389/fphar .2019 .00877

66. Younossi ZM (2019) Non-alcoholic fatty liver disease-a global public health perspective. J Hepatol 70(3):531-544. https://doi. org/10.1016/j.jhep.2018.10.033 